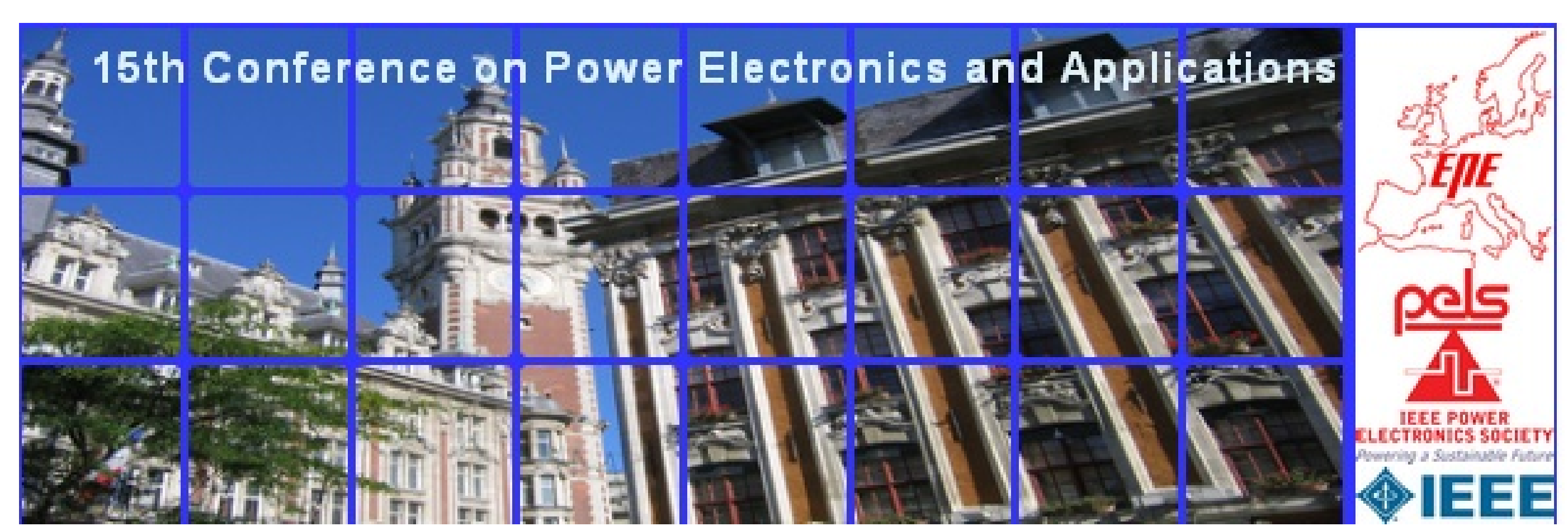

\title{
Two channel high voltage differential probe for power electronics applications
}

Alex Van den Bossche, Dimitar Bozalakov

Ghent University - EELAB

Sint-Pietersnieuwstraat 41

Gent, Belgium

Tel.: +32/9-264.34.19

Fax: $+32 / 9-264.35 .82$

E-Mail: alex.vandenbossche@ugent.be,mitko.bozalakov@gmail.com URL: http://www.ugent.be/en

\section{Highlights:}

- High voltage two channel differential probe for power electronics

- Bandwidth of at least $10 \mathrm{MHz}$

- Follow slew rate- $7.3 \mathrm{~V} / \mathrm{ns}$ at the input - typical in real power converters

- The probe is tested by using high voltage source up to $8 \mathrm{kV}$ DC and no corona or

flashover were observed between the PCB layout and the components

and between the components as well.

\section{Features}

Allows non ground referred measurements by avoiding the usage of expensive

galvanic insulated oscilloscopes

- Guaranties safety measurements up to $\pm 3 \mathrm{kV}$ in differential measurement (category II)

- Two channels - cost effective per channel

Probe overview

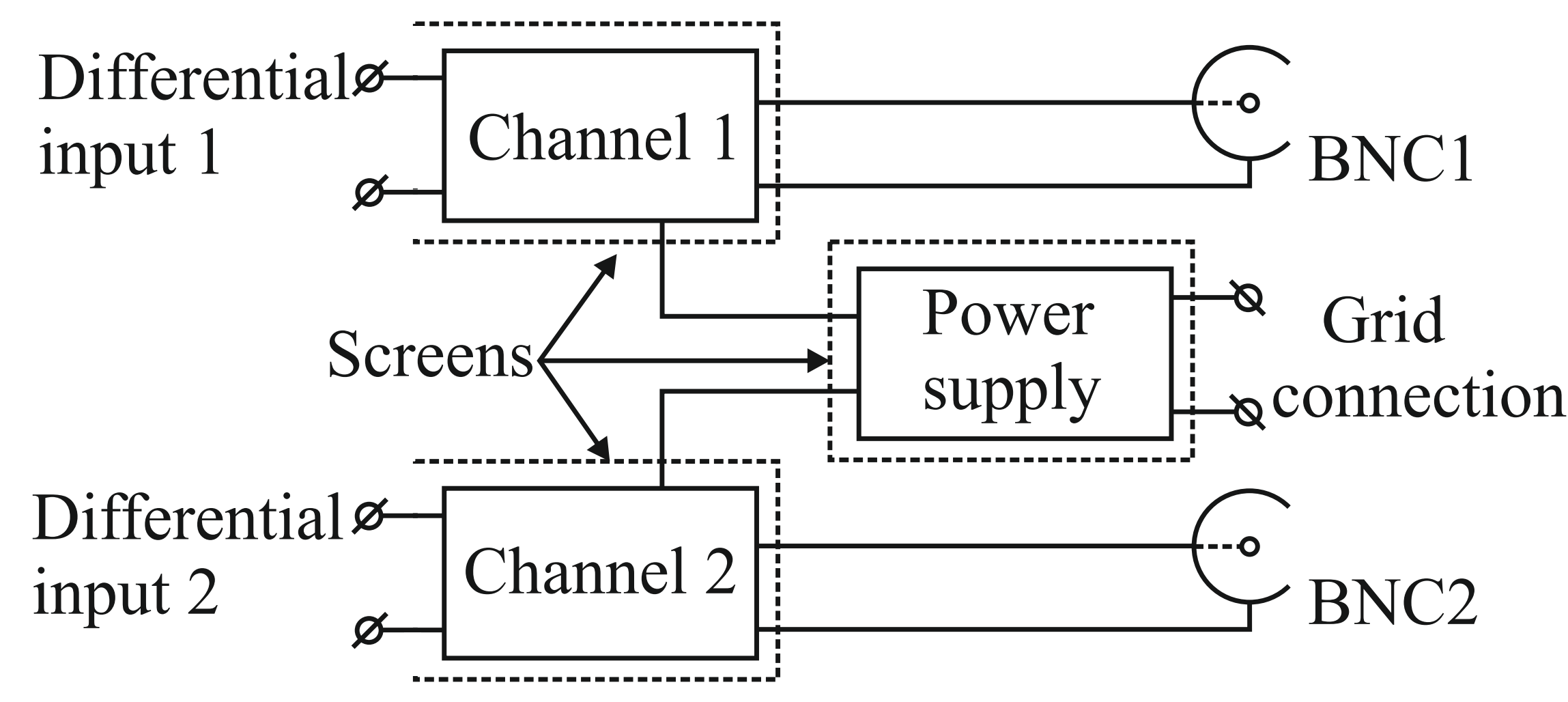

Fig. 1: Simplified block diagram of the probe

The accuracy of the high voltage resistors is $1 \%$ but they are checked for higher accuracy and 5\% for capacitors which are tuned by variable capacitor.

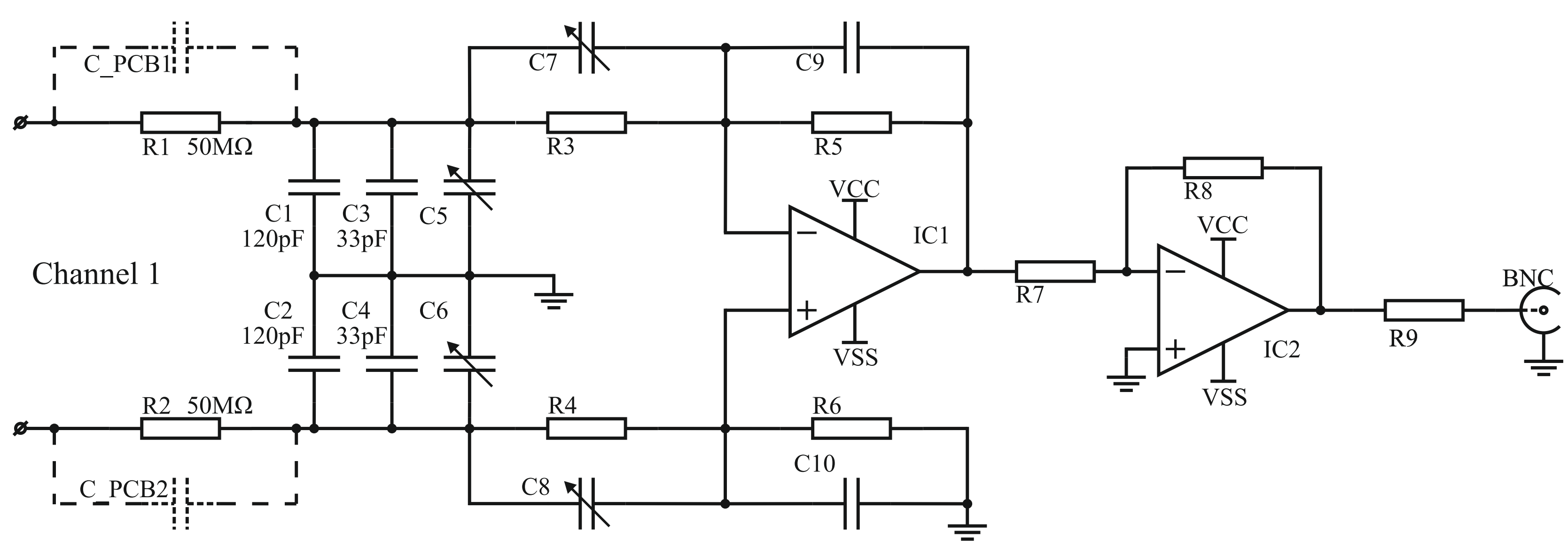

Fig. 2: Detailed schematic diagram of the probe

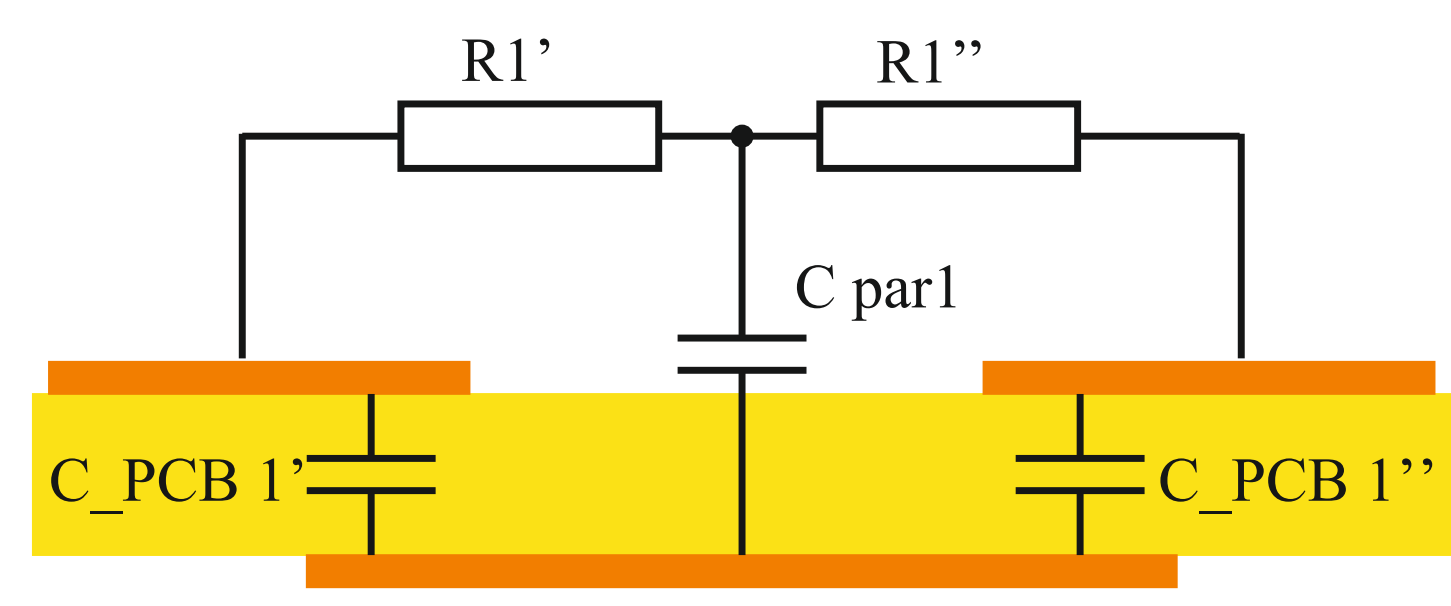

$\square$ Copper path $\square$ FR 4 PCB materia

Fig. 3: PCB capacitor implemented in the internal capacitive divider

\section{Experimental results}

\section{Bandwidth of the probe}

The parasitic capacitors make the flat bandwidth difficult, so a derivation of $2-3 \%$ is achieved.

One can obtain a somewhat higher bandwidth, but at the expense of the more complexity and more tuning

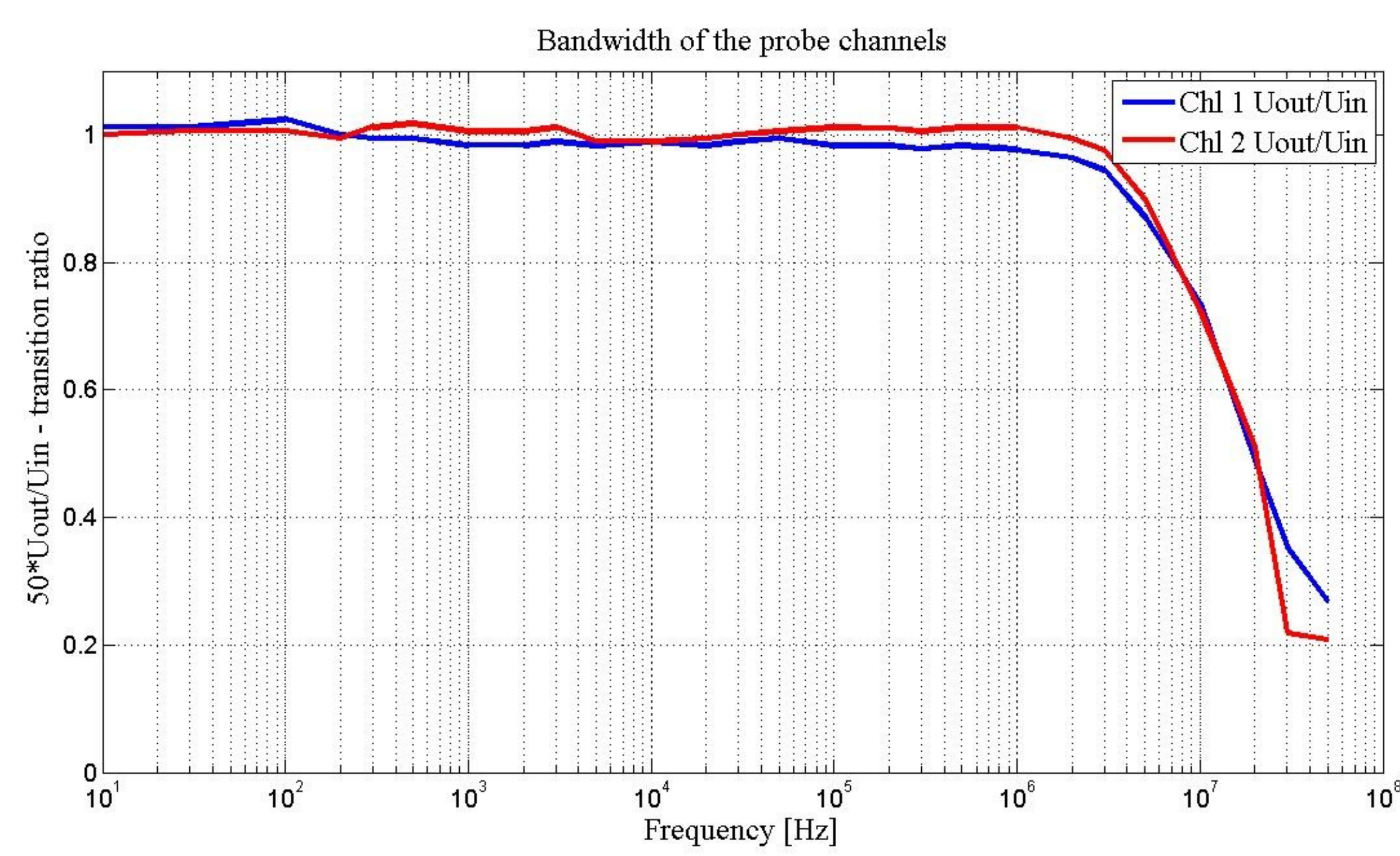

Fig. 4: Bandwidth of both channels of the probe

Test under rectangular pulses

Fig .5 to Fig. 8 show rectangular input pulses (blue channel) and output pulses (yellow) from the probe The input signal is about $33 \mathrm{~V}$ peak to peak and the tested frequencies are $-1 \mathrm{kHz}, 3 \mathrm{kHz}, 10 \mathrm{kHz}$, $30 \mathrm{kHz}, 100 \mathrm{kHz}$ and $300 \mathrm{kHz}$

The active output of the generator is connected to the inverting input of the probe

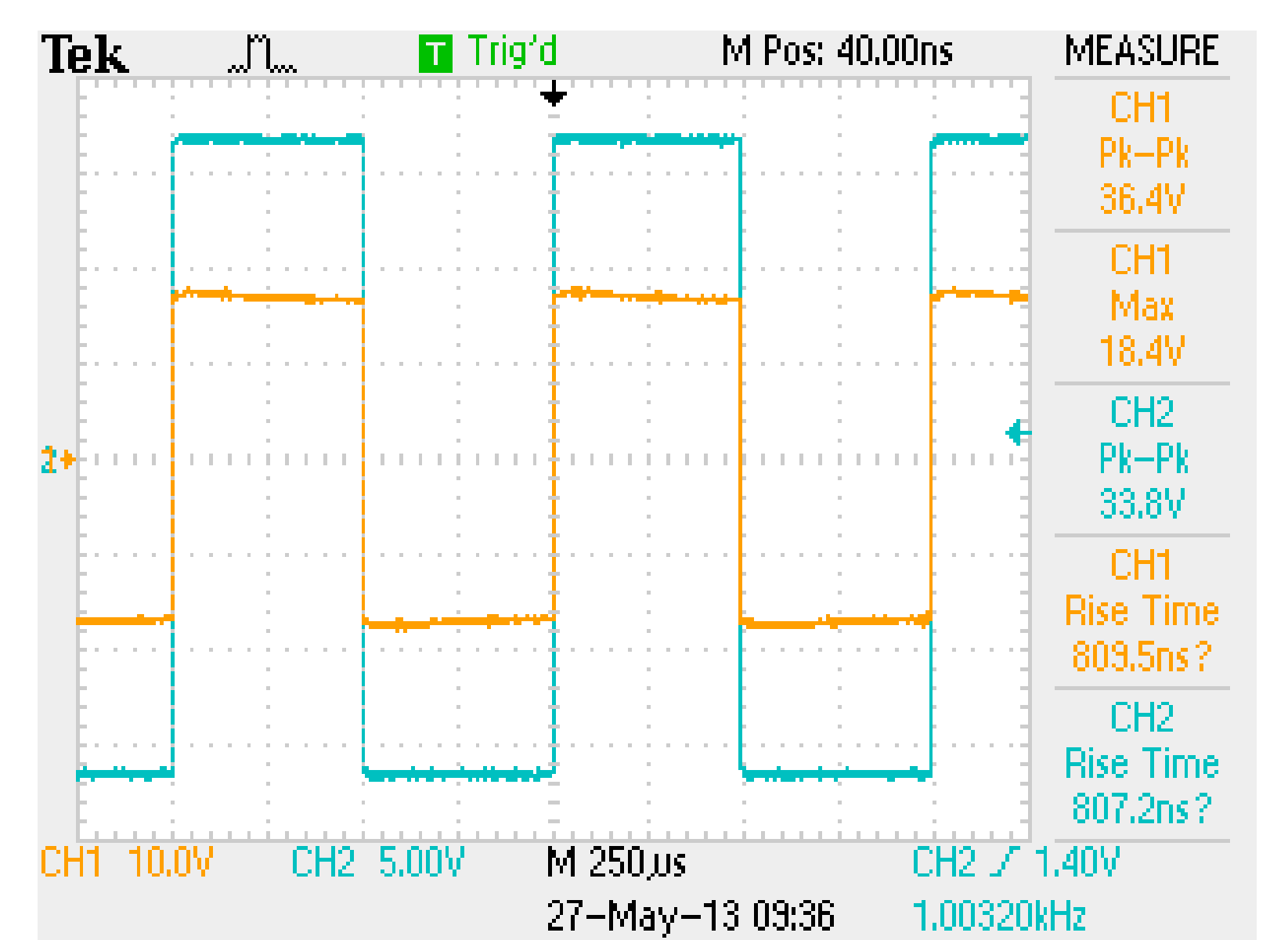

a) comparison at $1 \mathrm{kHz}$ Ch1 input, Ch2 output

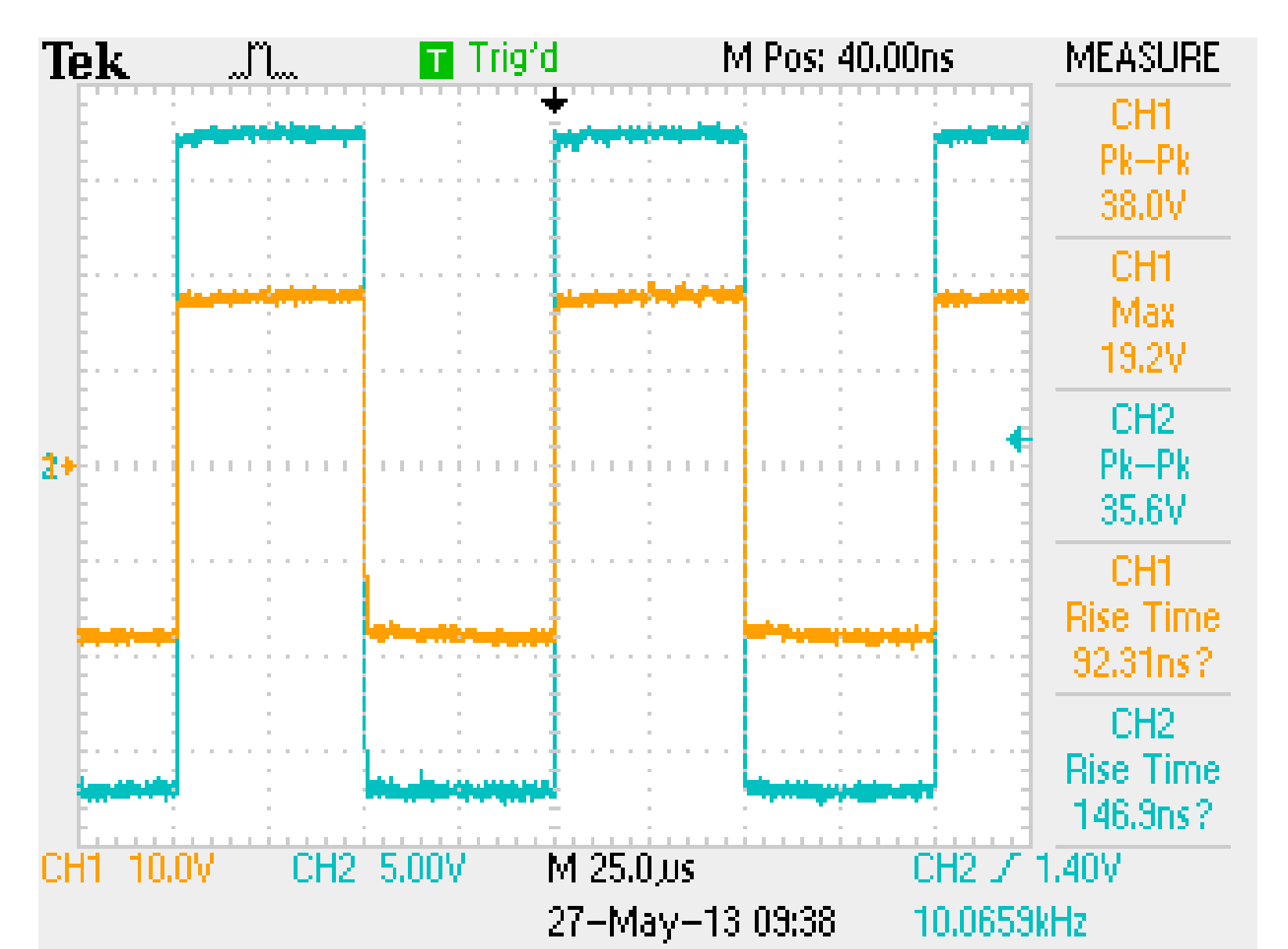

c) comparison at $10 \mathrm{kHz}$ Ch1 input, Ch2 output

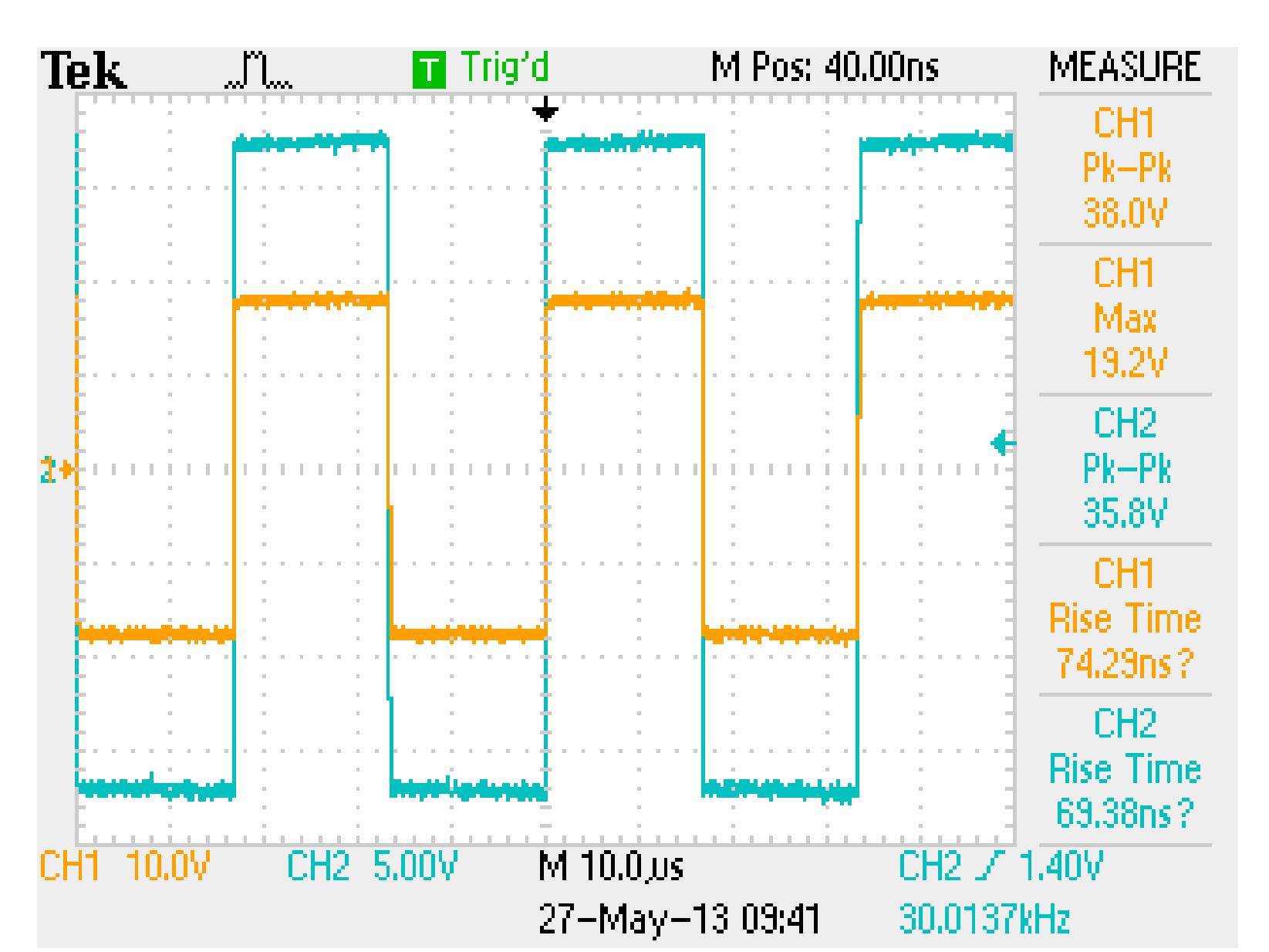

a) comparison at $30 \mathrm{kHz}$ Ch1 input, Ch2 output

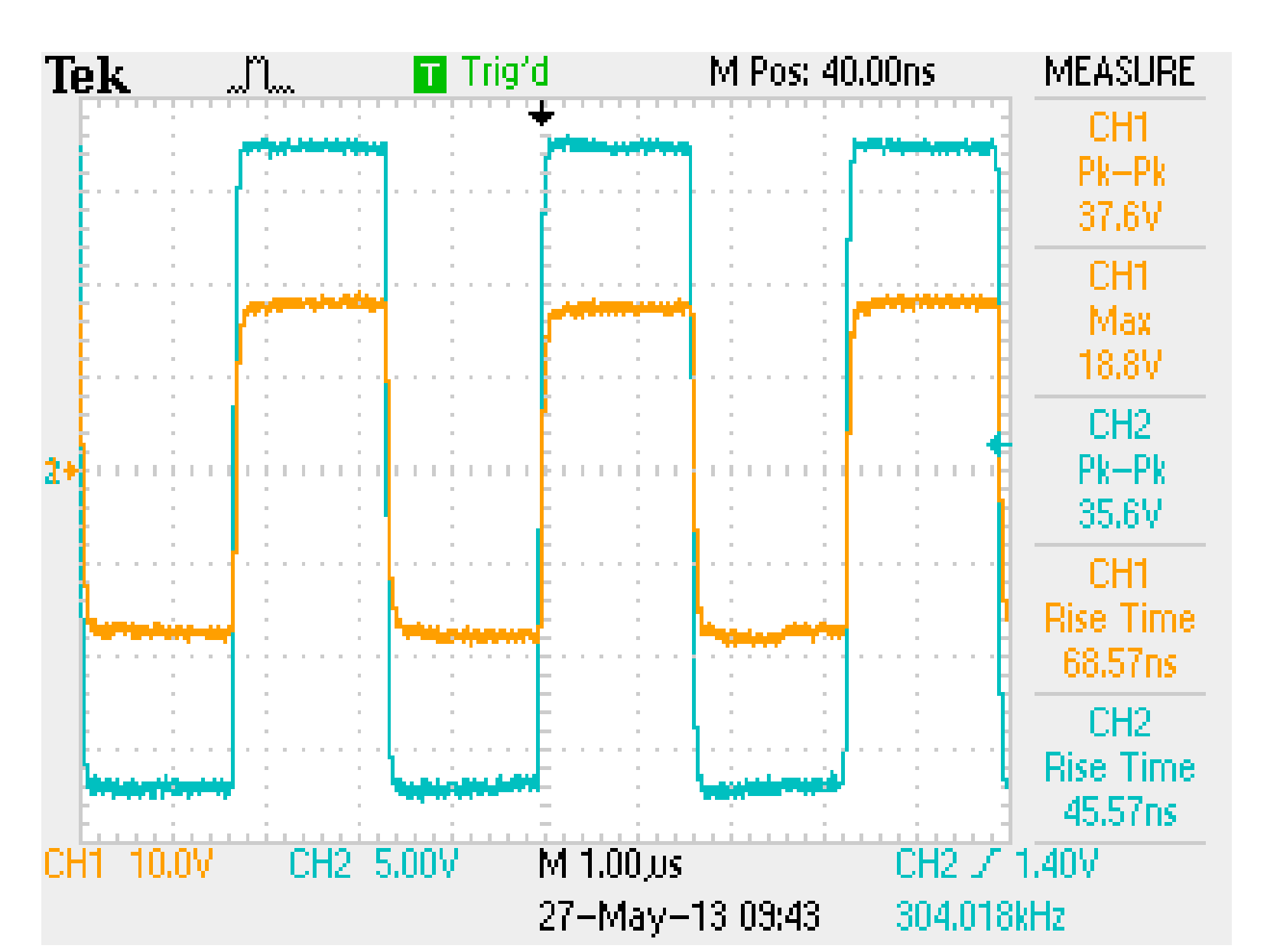

c) comparison at $10 \mathrm{kHz}$ Ch1 input, Ch2 output

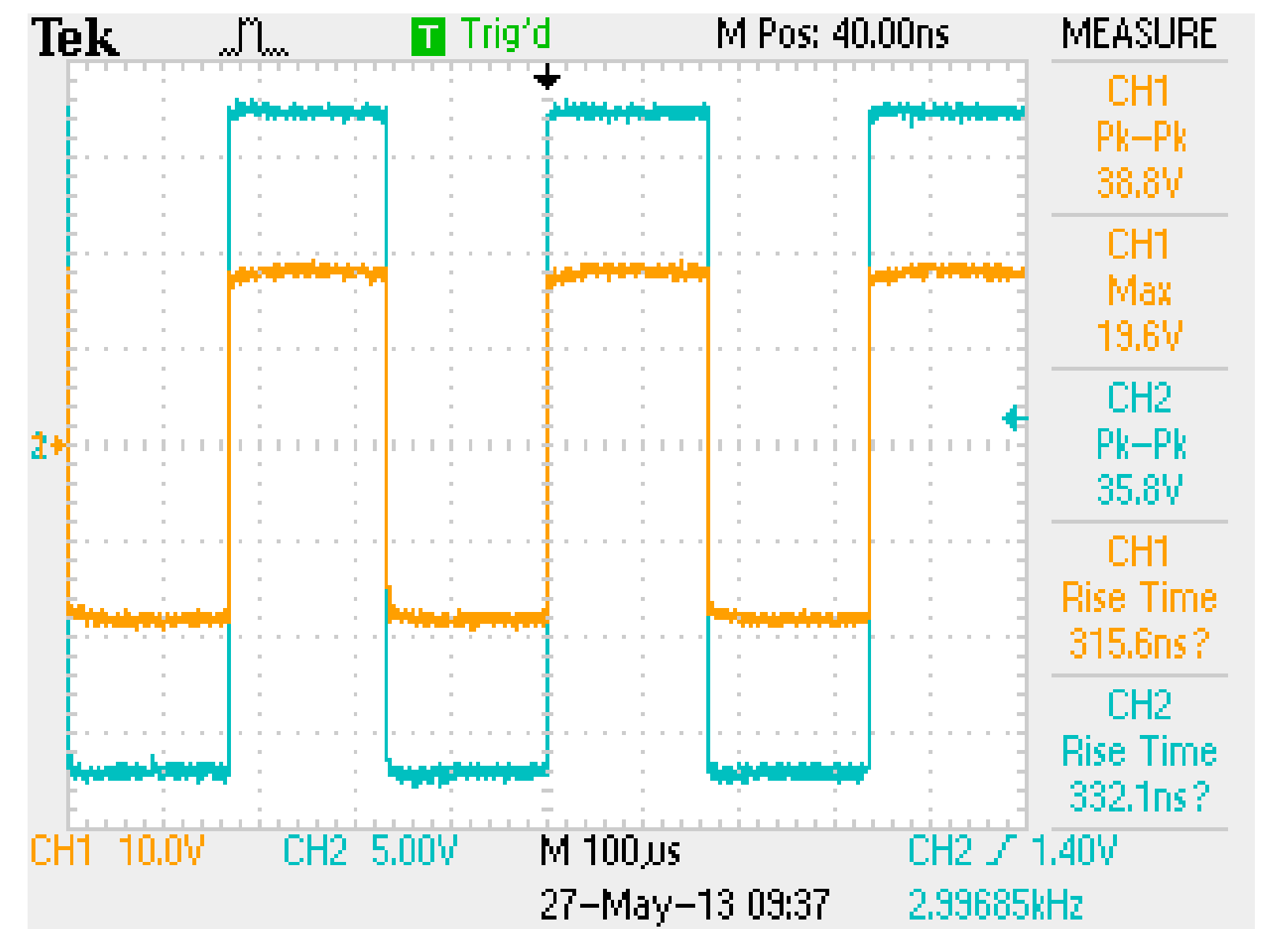

b) comparison at $3 \mathrm{kHz}$ Ch1 input, Ch2 output

Fig.5: Wave form comparison with $\mathrm{kHz}, 3 \mathrm{kHz}$ and $10 \mathrm{kHz}$ - active end of the generator is connected to the inverting input

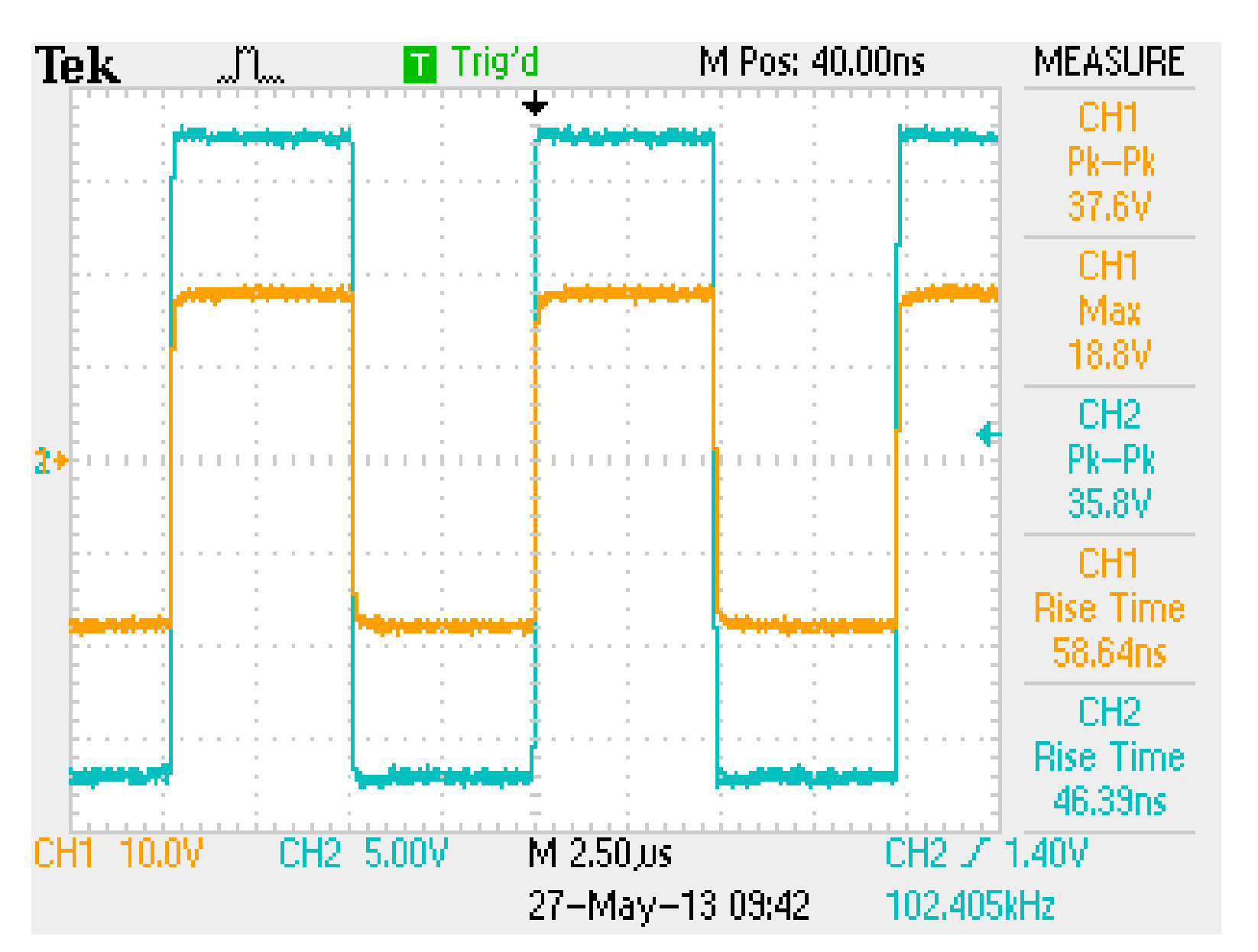

b) comparison at $100 \mathrm{kHz}$ Ch1 input, Ch2 output

Fig.6: Wave form comparison with different frequencies $30 \mathrm{kHz}, 100 \mathrm{kHz}$ and $300 \mathrm{kHz}$ - active end of the generator is connected to the inverting input 


\section{Two channel high voltage differential probe for power electronics applications}

The active output of the generator is connected to the non-inverting input of the probe

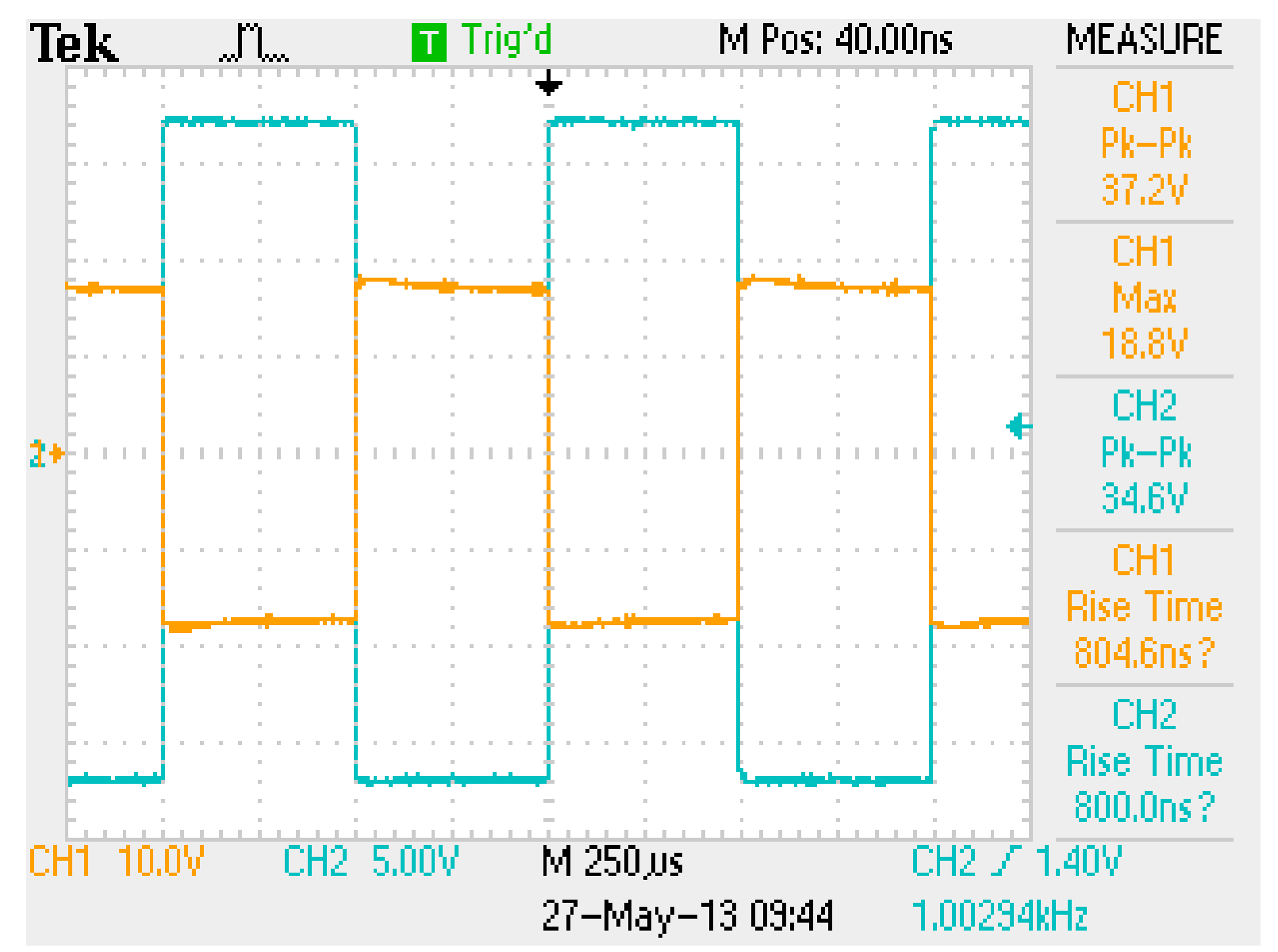

a) comparison at $1 \mathrm{kHz}$ Ch1 input, Ch2 output

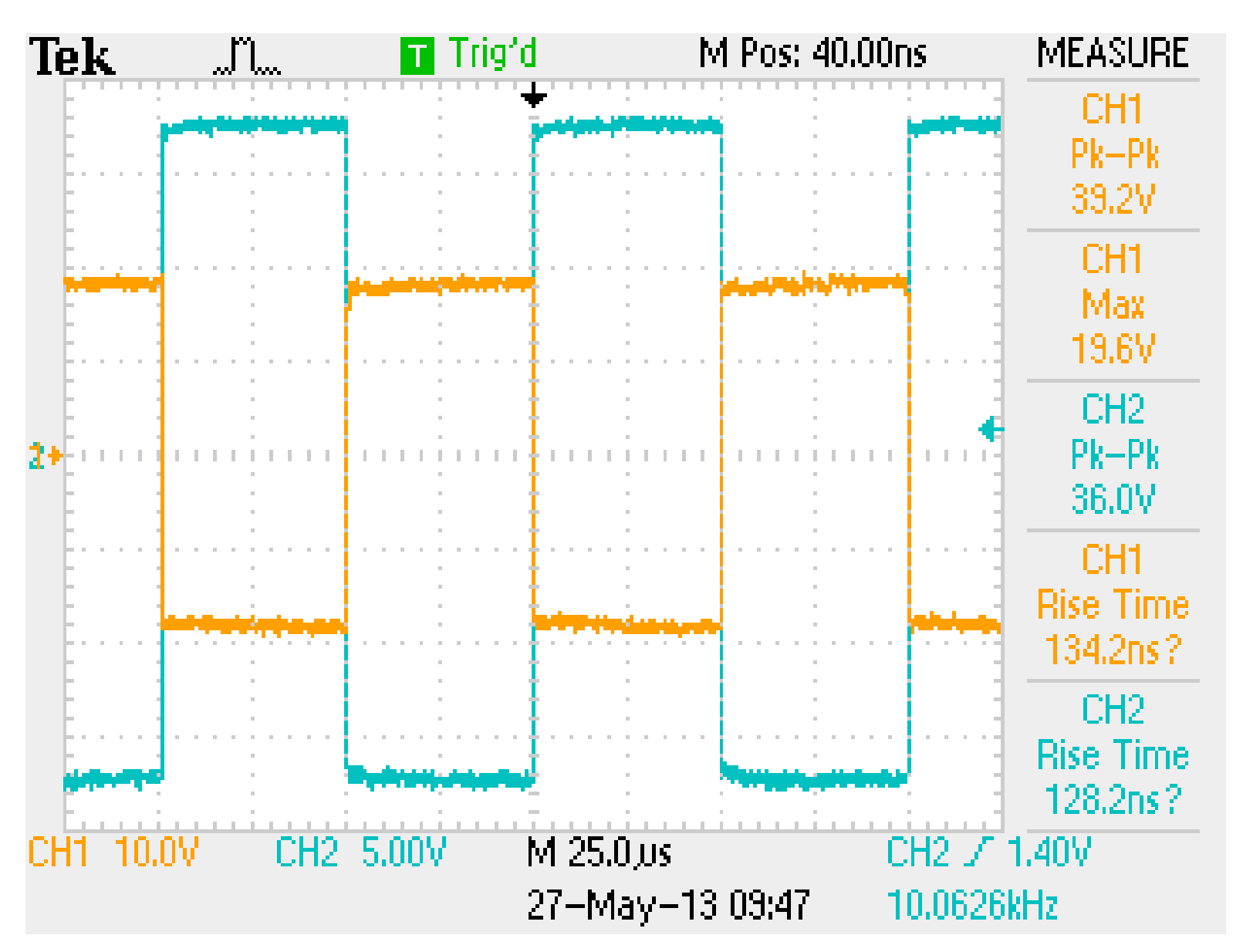

c) comparison at $10 \mathrm{kHz}$ Ch1 input, Ch2 output

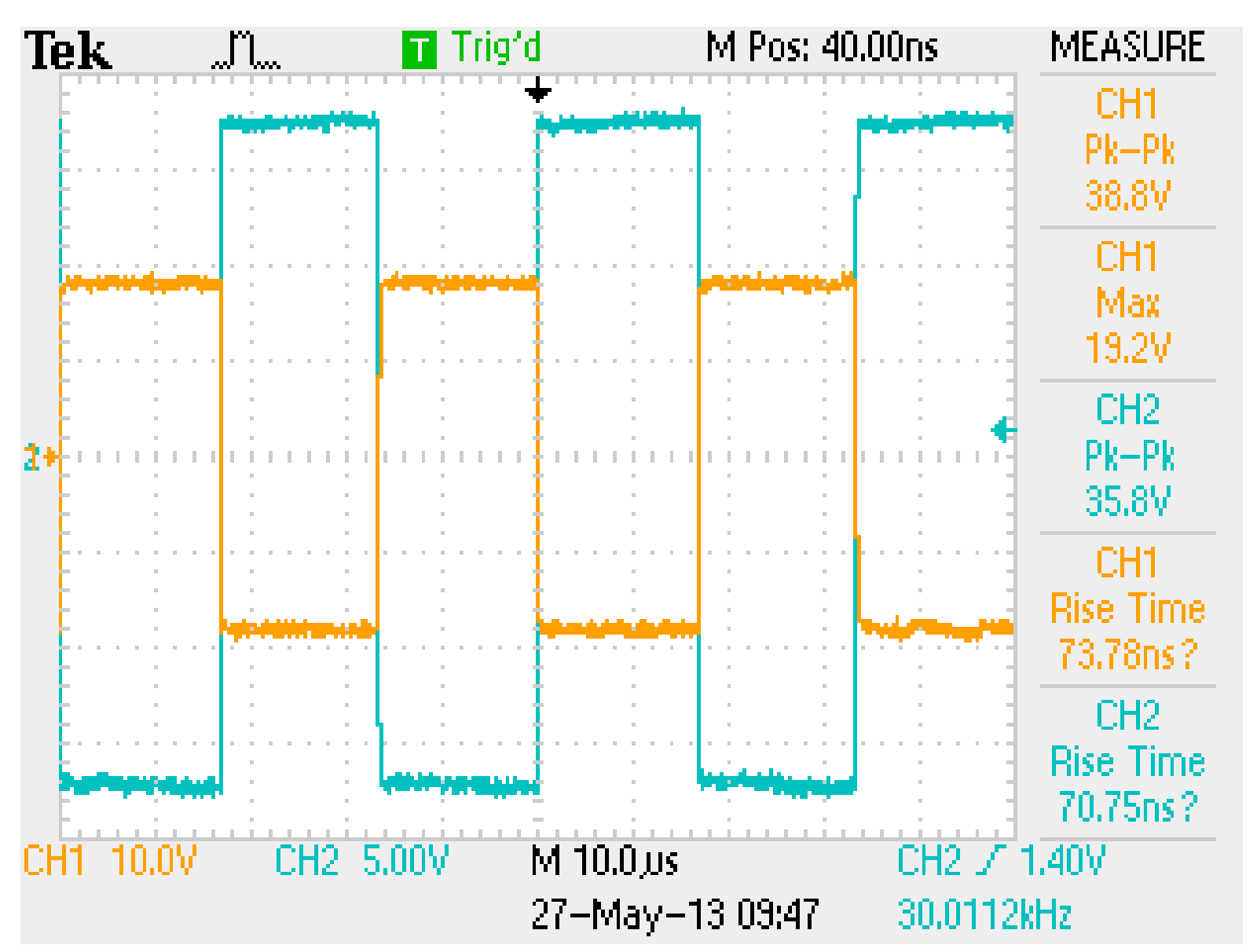

a) comparison at 30kHz Ch1 input, Ch2 output b) comparison at 100kHz Ch1 input, Ch2 output
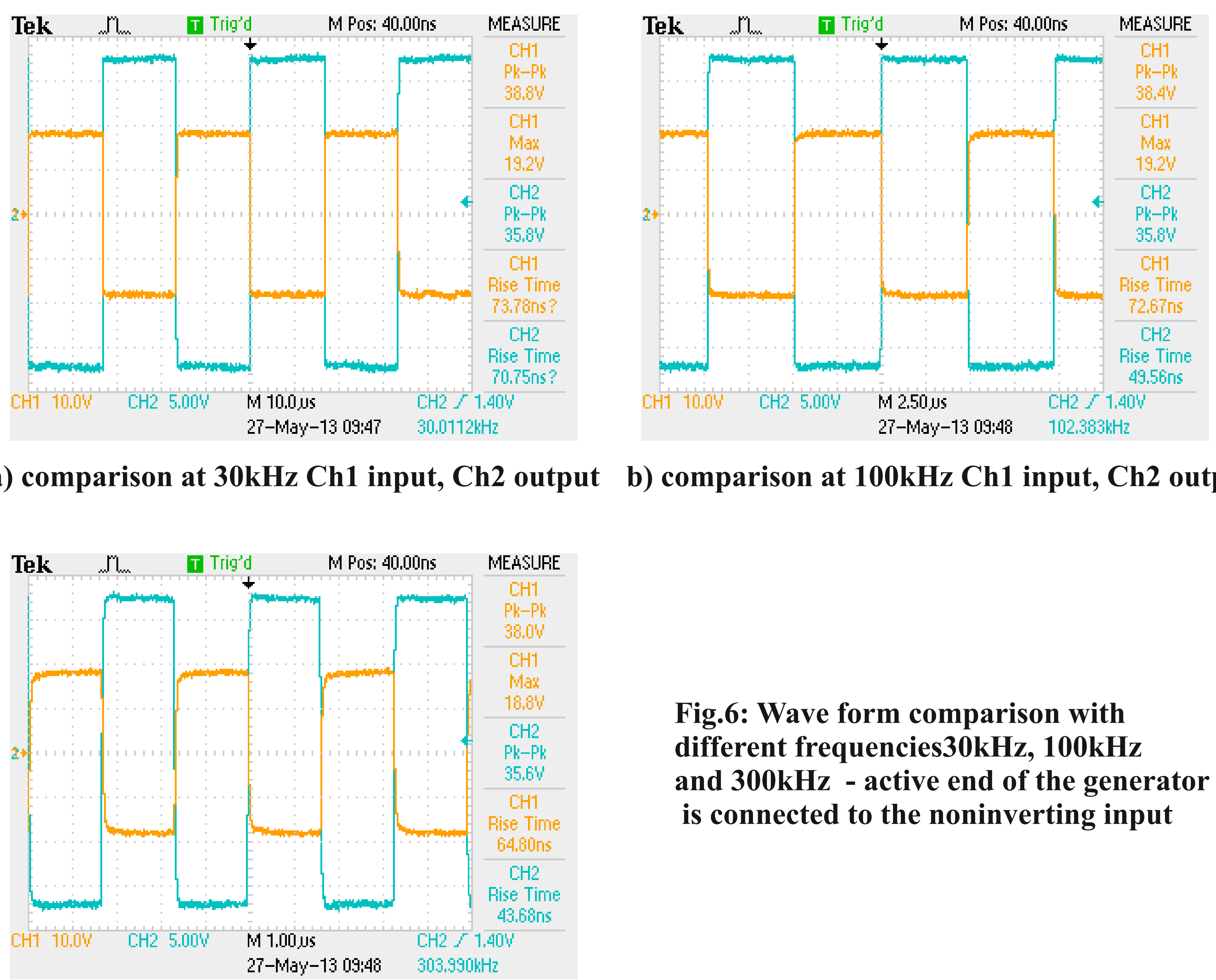
different frequencies $1 \mathrm{kHz}, 3 \mathrm{kHz}$ and $10 \mathrm{kHz}$ - active end of the generator
is connected to the noninverting input

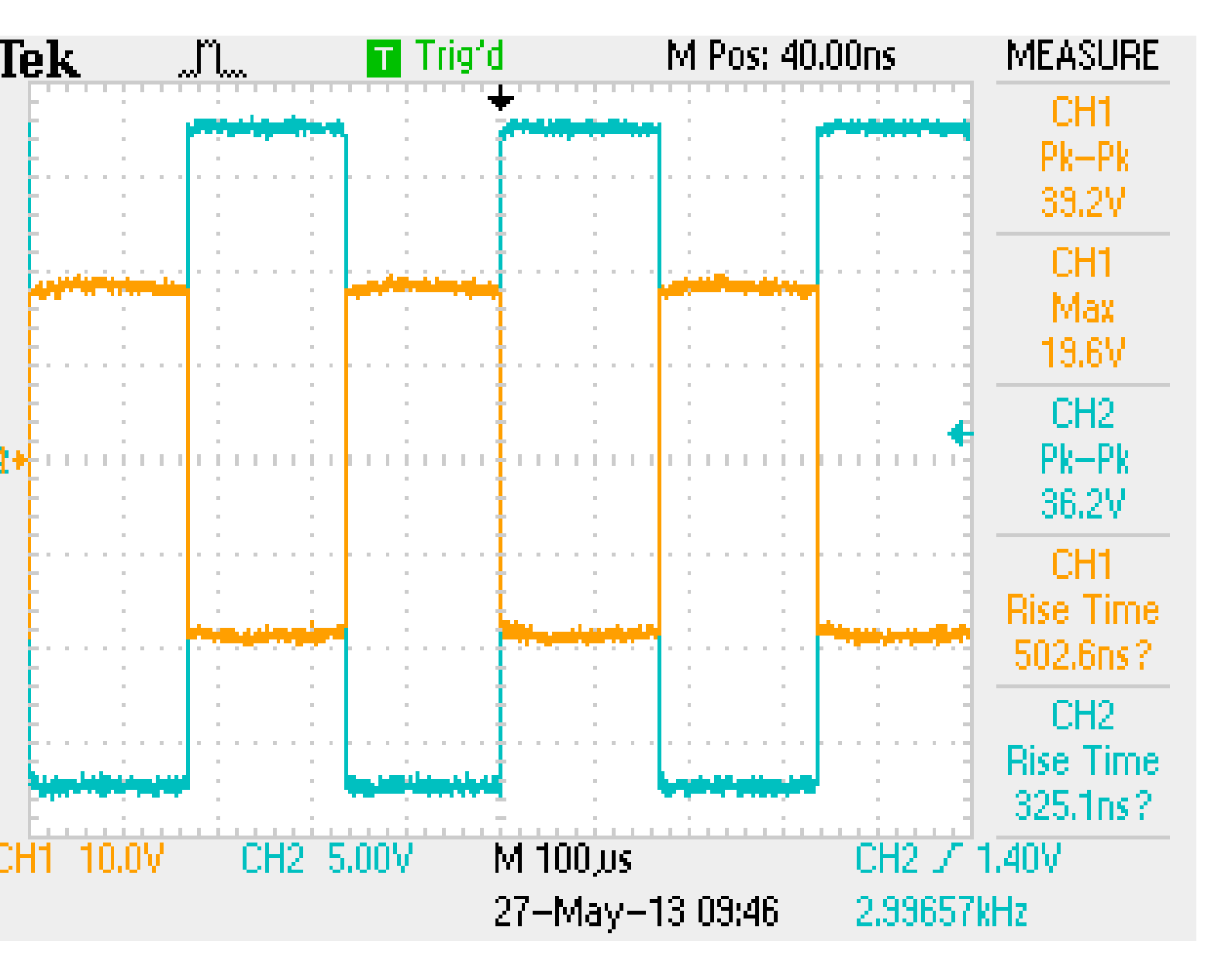

b) comparison at $3 \mathrm{kHz}$ Ch1 input, Ch2 output c) comparison at $10 \mathrm{kHz}$ Ch1 input, Ch2 output

Fig.6: Wave form comparison with different frequencies $30 \mathrm{kHz}, 100 \mathrm{kHz}$ and $300 \mathrm{kHz}$ - active end of the generator is connected to the noninverting input

We don't observe any overshoot spikes in the rising and falling edges and the pulses are very closer to the original ones. This is an important feature in converters as one wants to know the peak voltage occurring at the power components.

Pulse and edge comparison under high $\mathrm{dV} / \mathrm{dt}$ source

- Pulse source - DC chopper with amplitude of $330 \mathrm{~V}$ and slew rate of $7.3 \mathrm{~V} / \mathrm{ns}$

- Used scope - Tektronix TDS2014 together with high voltage probe P5120

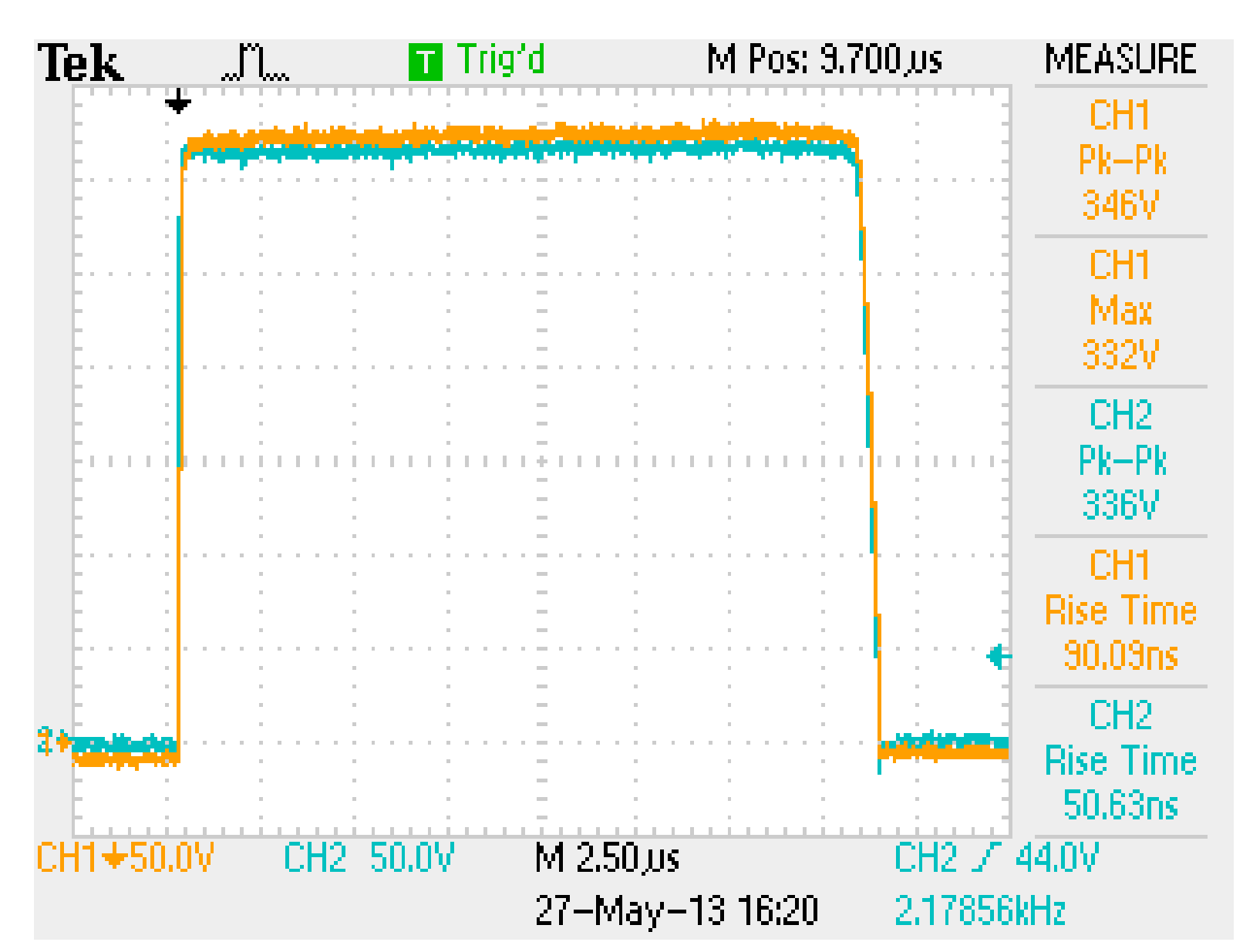

a) Pulse comparison - Ch1 output Ch2 input

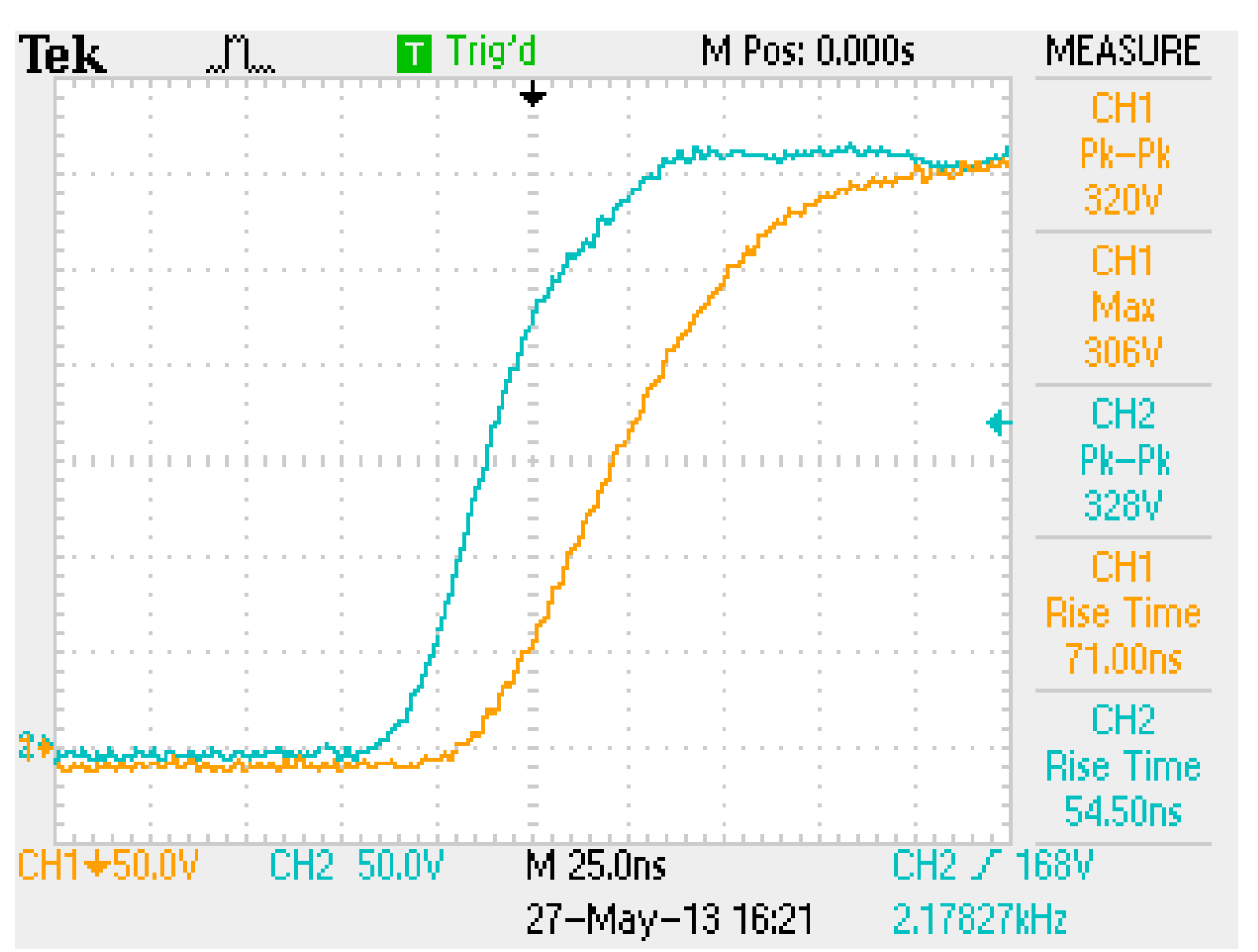

Fig.10: Wave form comparison at high $d V / d t$

The dv/dt of the input signal is close to $7.3 \mathrm{~V} / \mathrm{ns}$ or $220 \mathrm{~V} / 30 \mathrm{~ns}$ (channel 2 - blue) and as we can see the output (channel 1 - yellow) voltage is capable of following such high $d v / d t$ voltages.
CMRR test and CMRR under high dv/dt voltages

With the current settings of the components in the probe common mode rejection is roughly $40 \mathrm{~dB}$. - With the current settings of the components in the probe common mode rejection is roughly 40dB. but the amplitude is acceptable for at this level of design.

Input voltage - $344 \mathrm{~V}$, output voltage is $1.88 \mathrm{~V}$ multiplied by 50 from the scope, so we have abo ut $0.55 \mathrm{~V}$ output per $100 \mathrm{~V}$ input. Most of the gates driving pulses are above $10 \mathrm{~V}$, so in case of measurements such signals on the top transistors in an inverter supplied with $300 \mathrm{~V}$ the common mode voltage which will appear is $1.5 \mathrm{~V}$, so the differential probe is appropriate and for this kind of measurements as well.

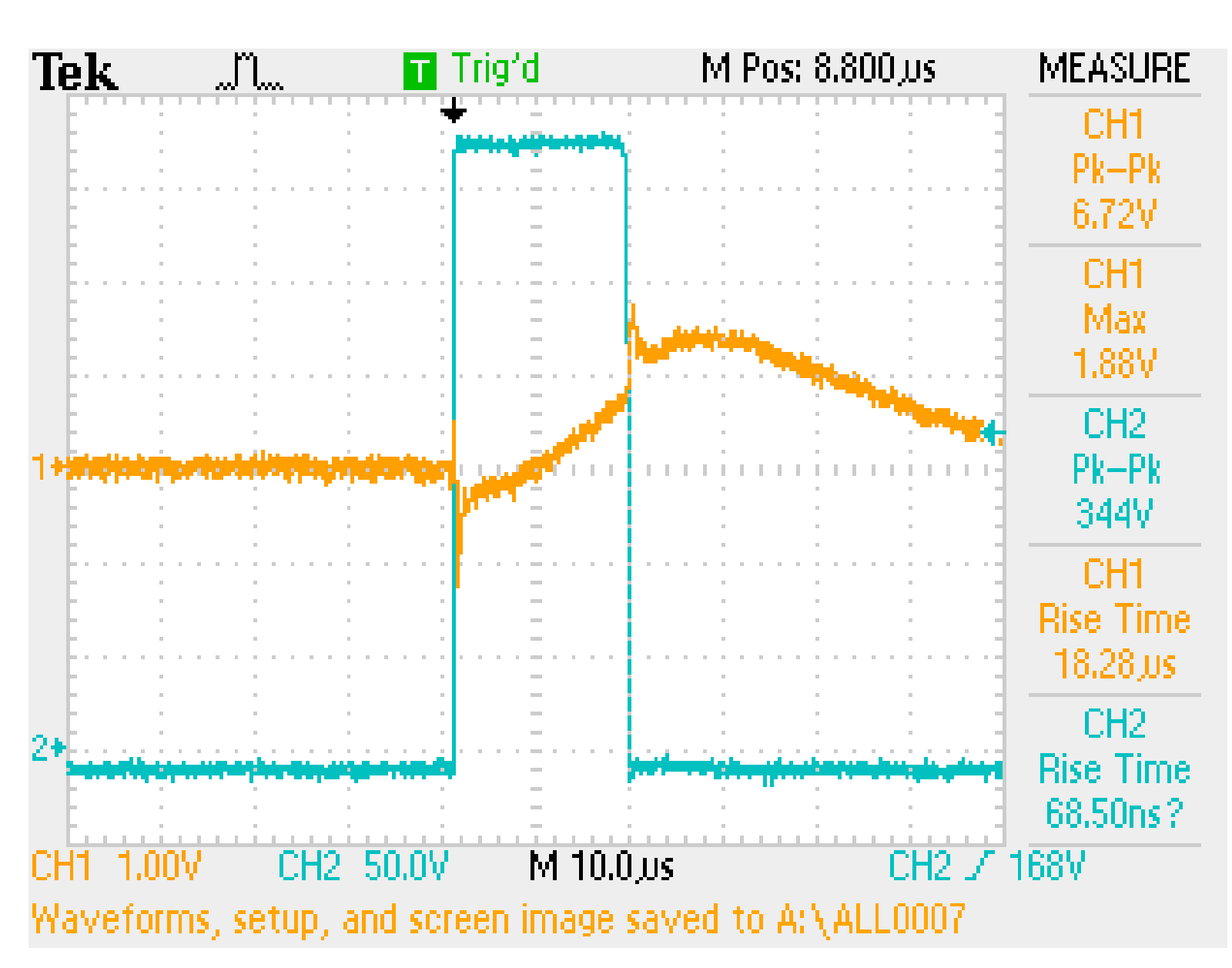

Fig.11: CM rejection at high $d V / d t$

\section{Final design}

-Symmetrical topology - similar performance between both channels
- Distance between the screens and the inputs - above $12 \mathrm{~mm}$ which provides enough safety margins for operational voltages screens and the in

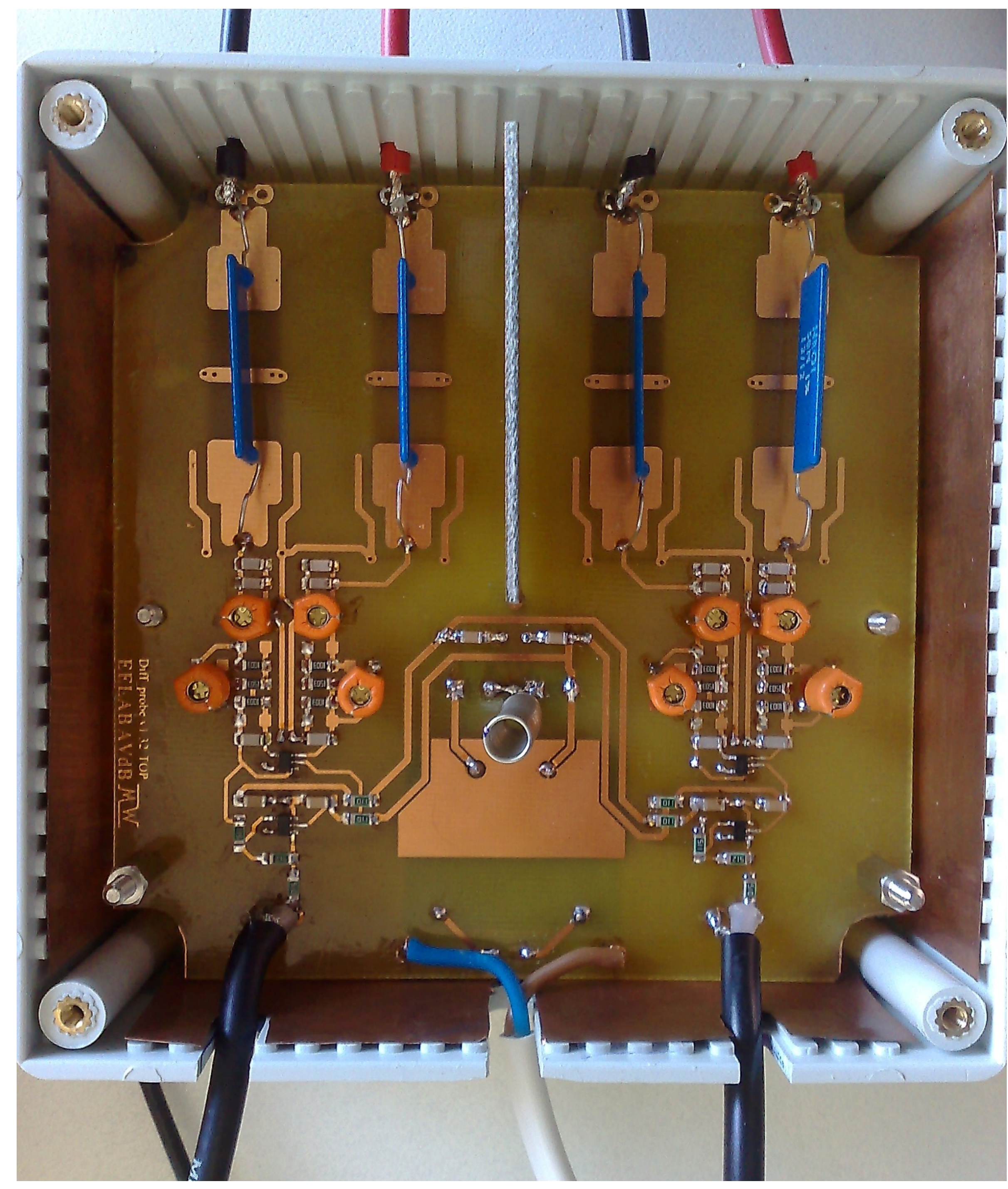

\section{Conclusions}

-A probe with very good performance is developed, specially adapted to the needs of didactical and development use in power electronics.

- The bandwidth is sufficient most of for power electronic applications, but special attention has been given to dv/dt aspects. It follows the slew rate of $5 \mathrm{~V} / \mathrm{ns}$ at $/ 50$ and $\mathrm{V} / \mathrm{ns}$ at highest attenuation of $/ 500$ and it displays square waves without overshoot.

- The small input capacitance and the very good CMMR, allows MOSFET and IGBT gate measurements in real power converters.

-The stand-by power is below $0.9 \mathrm{~W}$.

\section{Acknowledgments}

The work is in collaboration with the Belgian company more@mere, info@moreatmere.com, www.bgemc.com

\section{References}

[1]. http://www.farnell.com/datasheets/302311.pdf - TPS2014 model

2]. Mark I. Montrose, Edward M. Nakauchi "Testing for EMC Compliance: Approaches and Techniques" Wiley, 2004, ISBN 0-471-43308-X

3]. Henry W. Ott "Electromagnetic Compatibility Engineering" Wiley, 2009, ISBN 978-0-470-18930-6

4]. R. Pallàs-Areny, O. Casas "A hands-on approach to differential circuit measurements", Measurement Vol. 40, Issue 1, January 2007, pp. 8-14

[5]S.A. Witherspoon, J. Choma Jr. "The analysis of balanced linear differential circuits" IEEE Transactions on Education, 38 (1) (1995), pp. 40-50

6]. Water G. Jung "Op Amp Applications Handbook" Analog devices, 2004, ISBN 0-7506-7844-5

[7]. Maloney, T.J. "Improving the balanced coaxial differential probe for high-voltage pulse measurements" Portland, OR, 11-13 Sept. 2001, ISBN: 978-1-5853-7039-9, pp. $396-405$ 